\section{Actualidades Científicas}

1.

Os Sulfuretos de ferro são desde há muito reconhecidos como os componentes principais dos meteoritos, mas nunca foram detectados nas observações de objectos semelhantes a nebulosa solar primitiva. Isto coloca um dilemna porque o enxofre é um elemento abundante no cosmos. Foi agora evidenciado que uma banda larga, identificada em espectros de infravermelho de grãos de sulfureto de ferro de meteoritos e poeiras inter-estelares, [1] coincide com a observada em espectros do Observatório Espacial em Infra-Vermelho de objectos estelares recentes. A banda, previamente atribuída ao óxido de ferro, implica que os grãos de sulfureto de ferro constituem um importante, mas mas até agora desconhecido, componente do pó circum estelar.

\section{2.}

As reacções de oxidação envolvendo o radical hidroxilo $(\mathrm{OH})$ e o dióxido de hidrogénio $\left(\mathrm{HO}_{2}\right)$ - conhecidos genericamente por $\mathrm{HO}_{x}$ - têm um papel importante na química atmosférica por destruirem muitos poluentes. No entanto, dadas as sua pequeníssimas concentrações, da ordem de uma parte por trilião, foi difícil obter dados fiáveis sobre $\mathrm{HO}_{x}$ em sítios remotos. Medições de peróxido de hidrogénio $\left(\mathrm{H}_{2} \mathrm{O}_{2}\right)$ permitiriam uma estimativa da concentração de $\mathrm{HO}_{x}$, porque a reacção de duas moléculas de $\mathrm{HO}_{2}$ para dar $\mathrm{H}_{2} \mathrm{O}_{2}$ e $\mathrm{O}_{2}$ é a fonte principal de $\mathrm{H}_{2} \mathrm{O}_{2}$ na troposfera superior e na estratosfera. Infelizmente, medições feitas em balões deram concentrações mais pequenas na estratosfera do que era previsto por modelos, indicando que a compreensão actual das cinéticas governando a produção e a perda de $\mathrm{H}_{2} \mathrm{O}_{2}$ estava incompleta. Christensen et al. [2] refinaram a constante de cinética da reacção de formação de $\mathrm{H}_{2} \mathrm{O}_{2}$ a partir de $\mathrm{HO}_{2}$. A consideração do efeito do metanol (que muitas vezes é utilizado como precursor do $\mathrm{HO}_{2}$ ) sobre a reacção de formação produziu uma constante de velocidade mais pequena do

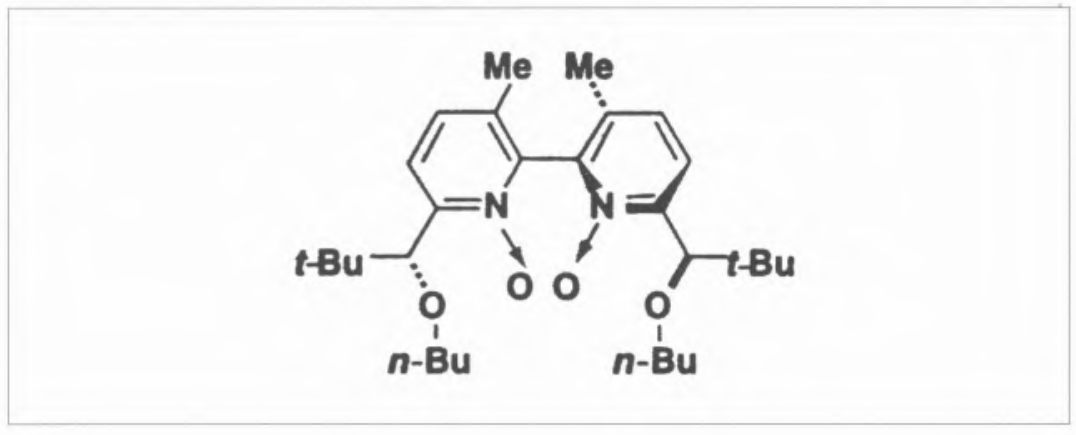

que a habitualmente recomendada, sobretudo a baixas temperaturas. Quando a constante de velocidade ajustada foi utilizada em simulação fotoquímica, foi obtido um bom acordo com o $\mathrm{H}_{2} \mathrm{O}_{2}$ medido.

\section{3.}

Existem vários métodos para controlar a estereoquímica da adição de cetonas e de ésteres a aldeídos para formar um aldol (o b-hidroxi-carbonilo). Métodos para conseguir a adição com cetonas um rendimento de cerca de $90 \%$ com excessos enantioméricos de 80 a $85 \%$.

4.

Os iões polioxometalatos (POM) existem sob a forma de grandes aglomerados que contêm iões metal e ligandos oxo. De entre estes, os iões Keggin, $\left[\mathrm{XM}_{12} \mathrm{O}_{40}\right]^{3-}$, onde $\mathrm{X}$ é um não-metal como PV ou um ião metal como $\mathrm{Fe}^{\text {II!, }}$ mas $\mathrm{M}$ um metal das primeiras séries dos elementos de transição como Mo, $\mathrm{V}$ ou $\mathrm{W}$, num estado de spin baixo $\mathrm{d}^{0}$. Bino

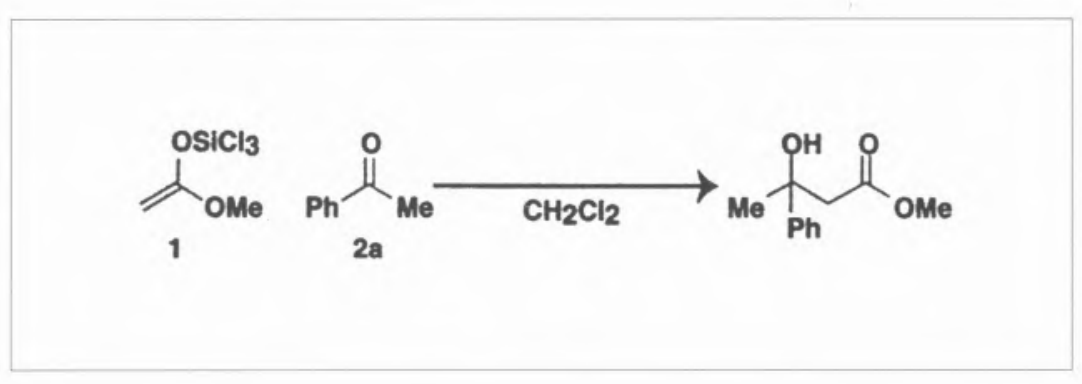

menos reactivas, em vez de aldeídos, são poucos e limitados a a-dicetonas e ésteres piruvados.

Estudos anteriores mostraram que o acetato de triclorosilil enolato de metilo (1) é muitíssimo reactivo com aldeídos, tão reactivo que é difícil controlar a estereoquímica dos produtos.

Denmark e Fan mostram agora [3] que (1) se adicionará a uma larga variedade de cetonas, como a acetofenona (2a), mas dum modo muitíssimo enantiosselectivo em presença de promotores $N$ óxido, por exemplo:

Estudos mecanísticos indicam que duas moléculas de catalisador estão envolvidas no estado de transição, e os autores descobriram que os bis- $N$-óxidos dão et al. [4] mostram agora que pode ser formado um ião Keggin onde X e M são átomos Fe ${ }^{\text {III }}$ no estado de spin alto, $d^{5}$, por incorporação de iões metoxi (OMe) e fluoreto. A espécie $\left[\mathrm{Fe}_{13} \mathrm{O}_{4} \mathrm{~F}_{24}(\mathrm{OMe})_{12}\right]^{5-}$ foi sintetizada com um rendimento de 20 $\%$ por reacção de $\mathrm{FeF}_{3} \cdot 3 \mathrm{H}_{2} \mathrm{O}$ e piridina em metanol quente. Fortes interacções de permuta foram inferidas a partir de medições preliminares de susceptibilidade magnética. Estes resultados abrem novas oportunidades de sintese para os POM, que encontraram muitas aplicações em ciência de materiais e catálise.

\section{5.}

Os ligandos multidendatos são moléculas orgânicas que contêm vários grupos funcionais, como os grupos $\mathrm{C}=\mathrm{O}$, que 
podem ser utilizados para ligar, ou quelar, um ião de metal de transição. Muitos ligandos habitualmente utilizados em química inorgânica não são verdadeiramente optimizados para a quelação e devem torcer-se consideravelmente durante a ligação, o que enfraquece a interacção total. Lumetta et al. [5] examinaram teoricamente a interacção de alguns ligandos habitualmente utilizados para ligar iōes actinídeos e lantanídeos, os malonamidos alquilados. Desenharam, então uma variante bi-cíclica onde os grupos $\mathrm{C}=\mathrm{O}$ estão orientados em ambos os confórmeros, cis e trans, de tal modo que favorecem uma estrutura de mais baixa energia que sofre apenas uma pequena reorganização durante a ligação. Em meio ácido, este ligando mostrou um aumento de sete ordens de grandeza na constante de ligação do $\mathrm{Eu}^{3+}$ quando comparada com a de vários malonamidos não cíclicos.

\section{6.}

As micelas e os vesículos formam-se em solução através de um jogo de efeitos hidrofóbicos e hidrofilicos. Os tamanhos e formas são muitissimo sensiveis a alterações de arquitectura das moléculas e a pequenas variações das condições de solvente. A maioria das micelas são de tipo estrela, consistindo num pequeno núcleo rodeado de um coroa espessa. No entanto, com copolímeros tribloco muitissimo assimétricos acontece o contrário: um grande núcleo está rodeado duma coroa fina (tipo "corte à escovinha"). Para produzir esses materiais, o polimero é dissolvido num solvente orgânico que acomoda ambos os blocos, e a água é adicionada a seguir. Com copolímeros tribloco constituídos por uma cadeia central, comprida, de de polistireno e por blocos terminais de isopreno funcionalizado, Riegel et al. [6] observaram uma nova morfologia de tipo bola que atribuem à coalescência de bolhas com a micela, que acontece quando a água é adicionada para retirar o solvente. Descobriram que as bolhas se formam preferencialmente para concentrações elevadas de polímero e somente em solventes que possam dissolver os dois homopolímeros. Foi observada uma larga dispersão de tamanhos o que indica que esta estrutura é só cineticamente estável mas não representa um estado de equilíbrio.

\section{7.}

Um novo método para produzir cerâmicas duras de nitreto de silício parece ser mais promissor e muito mais rápido do que as técnicas estabelecidas [7]. 0 processo de sinterização por descarga de plasma produz duras micro-estruturas, entrosadas, em alguns minutos a $1600{ }^{\circ} \mathrm{C}$. Mantendo o material a várias temperaturas, a cinética da reacção e, portanto, a morfologia e o tamanho dos grâos, pode ser influenciada num processo de "maturação dinâmica".

\section{8.}

Os químicos consideram habitualmente que as reacções químicas elementares ocorrem de modo estatístico - a energia é rapidamente redistribuída por modos vibracionais e rotacionais, e os mínimos de energia profundos, que se encontram ao longo dos vários caminhos de reacção possiviveis, tendem a actuar como "armadilha" e dominam a formação dos produtos. Sun et al. [8] apresentam resultados de simulações dinâmicas duma reacção de substituição nucleofilica, $\mathrm{OH}+\mathrm{CH}_{3} \mathrm{~F} \rightarrow \mathrm{CH}_{3} \mathrm{OH}+\mathrm{F}$; que mostra que, apesar da presença de um mínimo profundo na superfície de energia potencial, mais de $90 \%$ das trajectórias das simulaçōes vão dar aos produtos. A formação dos produtos parece acontecer numa escala de tempo muito mais rápida do que a concorrente redistribuição estatística de energia.

\section{9.}

Cortes e incisões, mesmo em tecidos frágeis como o olho, são muitas vezes tratados com suturas. Adesivos biodegradáveis poderiam oferecer a dupla vantagem de manter os bordos dos tecidos juntos com a pressão distribuída mais uniformamente e não requerendo a remoção manual após alivio. Carnahan et al. [9] sintetizaram poliéster-éte- res muitíssimo ramificados compostos de poli(etileno glicol), glicerol e ácido succínico e utilizaram estes polímeros para fechar cortes em olhos a que tinham sido extirpados tumores. Estas moléculas que têm um centro linear pequeno e duas terminações dendriméricas, têm uma fraca viscosidade e, portanto, podem espalhar-se sobre uma laceração do olho. Foi utilizada a luz de um laser de árgon para formar ligações cruzadas no polimero, criando um filme elástico e transparente que selou uma laceração da córnea de 4,1 mm de espessura (espessura total) contra uma pressão de cerca 170 mm Hg (a pressão intraocular normal é de cerca 20 $\mathrm{mm} \mathrm{Hg}$ ou 2,7 kPa).

\section{Referências}

[1] L. P. Keller, S. Hony, J. P. Bradley, F. J. Molster, L. B. F. M. Waters, J. Bouwman, A. de Koter, D. E. Brownlee, G. J. Flynn, T. Henning, H. Mutschke, Nature 417 (2002) 148 .

[2] L. E. Christensen, M. Okumura, S. P. Sander, R. J. Salawitch, G. C. Toon, B. Sen, J.-F. Blavier, K. W. Jucks, Geophys. Res. Lett. 29 (2002) 10.1029/2001GL014525.

[3] S. E. Denmark, Y. Fan, J. Am. Chem. Soc. 124 (2002) 4233.

[4] A. Bino, M. Ardon, D. Lee, B. Spingler, S. J. Lippard, J. Am. Chem. Soc. 124 (2002) 4578.

[5] G. J. Lumetta, B. M. Rapko, P. A. Garza, B. P. Hay, R. D. Gilbertson, T. J. R. Weakley, J. E. Hutchison, J. Am. Chem. Soc. 124 (2002) 5644

[6] I. C. Riegel, A. Eisenberg, C. L. Petzhold, D. Samios, Langmuir 18 (2002) 3358.

[7] Z. Shen, Z. Zhao, H. Peng, M. Nygren, Nature 417 (2002) 266.

[8] L. Sun, K. Song, W. L. Hase, Science 296 (2002) 875

[9] M. A. Carnahan, C. Middleton, J. Kim, T. Kim, M. W. Grinstaff, J. Am. Chem. Soc. 124 (2002) 5291.

Olivier Pellegrino, revisã̃o de A. M. Botelho do Rego 